\title{
Comparação de procedimentos de quantificação de nitrato em tecido vegetal
}

\author{
José Ricardo Mantovani( ${ }^{(1)}$, Mara Cristina Pessôa da Cruz ${ }^{(1)}$, Manoel Evaristo Ferreira(1) e José Carlos Barbosa ${ }^{(2)}$ \\ (1)Universidade Estadual Paulista (Unesp), Faculdade de Ciências Agrárias e Veterinárias (FCAV), Dep. de Solos e Adubos, Via de Acesso \\ Prof. Paulo Donato Castellane s/no, CEP 14884-900 Jaboticabal, SP. E-mail: mantovanijr@yahoo.com, mcpcruz@fcav.unesp.br, \\ evaristo@fcav.unesp.br(2)Unesp, FCAV, Dep. de Ciências Exatas. E-mail: jcbarbosa@fcav.unesp.br
}

Resumo - O teor de nitrato é um importante índice da qualidade dos alimentos, mas existem problemas na sua quantificação. O objetivo deste trabalho foi comparar procedimentos de quantificação de nitrato em tecido vegetal. Em amostras de matéria seca da parte aérea de três cultivares de alface adubadas com cinco doses de nitrogênio, provenientes de experimento realizado em casa de vegetação, foi feita extração de nitrato com água desionizada e quantificação, utilizando os procedimentos da coluna redutora contendo cádmio, da destilação, do ácido salić́lico e da mistura redutora contendo zinco. Os procedimentos do ácido salicílico e da mistura redutora contendo zinco superestimam os teores de nitrato na matéria seca de alface, pois são mais sujeitos à presença de interferentes e ao efeito da cor do extrato. Os procedimentos da coluna redutora contendo cádmio e o da destilação são os mais adequados na quantificação de nitrato em tecido vegetal. Contudo, a simplicidade e o menor custo da destilação em relação à coluna redutora indicam que a destilação deve ser recomendada.

Termos para indexação: Lactuca sativa, análise de plantas, nitrogênio.

\section{Comparison of procedures for nitrate determination in vegetable tissue}

\begin{abstract}
Nitrate content determination is important for food quality evaluation, but its determination is affected by interferences. The objective of this work was to compare nitrate determination procedures for vegetable tissues. In dry matter samples from three lettuce cultivars that received five levels of nitrogen in a greenhouse experiment, nitrate was extracted with deionized water and its determination was made by the cadmium column method, the distillation method, the salicylic acid method, and the method using the reductive mixture with zinc. The salicylic acid method and that of reductive mixture with zinc overestimated the nitrate content in lettuce dry matter, because they were influenced by the color of dry matter extracts and other interferences. The cadmium column and the distillation methods are the best for nitrate determination in vegetable tissues, but the simplicity and lower cost of distillation in relation to cadmium column method suggest that the first one must be recommended.
\end{abstract}

Index terms: Lactuca sativa, plant analysis, nitrogen.

\section{Introdução}

A concentração de nitrato é um importante índice da qualidade dos alimentos. Quando ingerido pelo homem, o nitrato sofre ação microbiana na saliva e é reduzido a nitrito, o qual reage com aminas e dá origem a compostos nitrosos, como as nitrosaminas, que são carcinogênicos. Em crianças, o nitrito pode provocar a metemoglobinemia, doença que causa o impedimento do transporte de oxigênio dos alvéolos pulmonares para os tecidos, o que pode levar à morte (Wolff \& Wasserman, 1972; Swann, 1975).

A quantificação de nitrato em extratos de diferentes origens pode ser feita por colorimetria, destilação, potenciometria, espectrofotometria na região ultravioleta, cromatografia gasosa e cromatografia líquida (Sah, 1994; Anderson \& Case, 1999; Salomez \& Hofman, 2002), mas alguns desses procedimentos não são eficientes para extratos de plantas (Sah, 1994). A medida colorimétrica é a mais utilizada e aceita na análise de plantas por causa da sua simplicidade, baixo custo e precisão elevada.

A determinação de nitrato por colorimetria pode ser feita direta ou indiretamente. Na determinação direta, são utilizados o ácido fenoldissulfônico (Johnson \& Ulrich, 1950) ou o ácido salicílico (Cataldo et al., 1975). Na determinação indireta, conforme Ulrich (1948), e no método proposto por Follett \& Ratcliff (1963), o nitrato 
é reduzido a nitrito, o qual é quantificado (Sah, 1994). A determinação indireta do nitrato apresenta vantagens em relação à direta: maior sensibilidade, maior precisão e melhor seletividade, ou seja, é menos sujeita à interferência de outros íons (Sah, 1994).

Variações significativas nos teores de nitrato em extratos de planta são obtidas ao se compararem técnicas de quantificação do íon em um mesmo extrato e, assim, há necessidade de padronização de procedimento (Anderson \& Case, 1999; Salomez \& Hofman, 2002). A quantificação de nitrato em extratos de plantas por colorimetria, em que o nitrato é reduzido a nitrito, foi mais vantajosa do que a feita por eletrodo seletivo, por ser mais precisa, especialmente quando os teores de $\mathrm{N}$ na forma de nitrato $\left(\mathrm{N}^{-} \mathrm{NO}_{3}{ }^{-}\right)$foram menores que $80 \mathrm{mg} \mathrm{kg}^{-1}$, e menos sujeita à ação de íons interferentes, tal como a causada por $\mathrm{Cl}^{-}$(Jackson, 1980; Taber \& Killorn, 1993).

Na maioria dos trabalhos realizados no Brasil (Ricci et al., 1995; Castro \& Ferraz Júnior, 1998; Zago et al., 1999; Lédo et al., 2000; Beninni et al., 2002), a quantificação de nitrato em extratos de plantas foi feita segundo Cataldo et al. (1975), e suas vantagens, segundo os autores, são o maior rendimento, o menor custo e a facilidade de execução.

$\mathrm{Na}$ determinação de nitrato em carnes e demais alimentos, o método oficial estabelecido pelo Ministério da Agricultura e Abastecimento (Brasil, 1999) é o que promove a redução do nitrato a nitrito em meio alcalino pela passagem do extrato em coluna contendo $\mathrm{Cd}$ esponjoso, com posterior quantificação do $\mathrm{N}$ na forma de nitrito $\left(\mathrm{N}-\mathrm{NO}_{2}{ }^{-}\right)$por colorimetria. Esse procedimento foi proposto por Follett \& Ratcliff (1963), para análise de nitrato e nitrito em carnes e seus derivados, e simplificado por Lara et al. (1978). Ele é utilizado pelo Instituto Adolfo Lutz, responsável por emitir laudos sobre contaminação de alimentos no Estado de São Paulo e apresenta como desvantagens ser trabalhoso, necessitar do uso de vários reagentes e expor o analista a eventuais riscos de saúde pelo contato com o cádmio (Sah, 1994).

Outro procedimento colorimétrico de determinação indireta do nitrato é o descrito em Ulrich (1948) e modificado conforme Moraes \& Cantarella (2003). Nesse procedimento, a redução do nitrato a nitrito é feita por uma mistura redutora contendo $\mathrm{Zn}$ em pó, $\mathrm{BaSO}_{4}$ e $\mathrm{MnSO}_{4}$ e apresenta como desvantagem a redução pelo Zn, pois esta reação é afetada pela temperatura e pelas condições do meio, e não é completa, pois nem todo o nitrato é reduzido no tempo de reação utilizado e, assim, há necessidade de fazer uma curva de calibração para cada lote de amostras, em cada dia de análise.

O procedimento proposto por Bremner \& Keeney (1965), em que o $\mathrm{N}^{-\mathrm{NO}_{3}}$ - é determinado por destilação dos extratos em microdestilador Kjeldahl e subsequiente titulação do destilado, foi proposto inicialmente para solo, mas também pode ser utilizado em tecido vegetal, e apresenta vantagens em relação aos procedimentos colorimétricos, como ser livre de interferentes e não sofrer influência da cor do extrato.

Estudos comparativos entre os procedimentos de quantificação de nitrato em plantas, apesar de servirem de base para a definição do procedimento a ser usado, são escassos.

O objetivo deste trabalho foi comparar procedimentos de quantificação de nitrato em tecido vegetal.

\section{Material e Métodos}

A determinação de nitrato foi feita em amostras de matéria seca da parte aérea de alface proveniente de experimento realizado em casa de vegetação, no qual se utilizou amostra da camada arável $(0-20 \mathrm{~cm})$ de um Argissolo Vermelho-Amarelo distrófico, coletado em área de pastagem, com a seguinte caracterização química: $\mathrm{P}$ resina, $8 \mathrm{mg} \mathrm{dm}^{-3}$; $\mathrm{MO}, 37 \mathrm{~g} \mathrm{dm}^{-3} ; \mathrm{pH} \mathrm{em} \mathrm{CaCl}_{2}$ $0,01 \mathrm{molL}^{-1}, 4,8 ; \mathrm{K}^{+}, \mathrm{Ca}^{2+}, \mathrm{Mg}^{2+}, \mathrm{H}+\mathrm{Al}, \mathrm{SB}$ e CTC, respectivamente, 2,1, 22, 10, 38, $34 \mathrm{e} 72 \mathrm{mmol}_{\mathrm{c}} \mathrm{dm}^{-3} ; \mathrm{e} \mathrm{V}, 47 \%$.

Os tratamentos consistiram da combinação fatorial de cinco doses de $\mathrm{N}$ e três cultivares de alface, com quatro repetições, em delineamento em blocos ao acaso. Foram usadas $0,141,5,283,566$ e $1.132 \mathrm{mg} /$ vaso de N (uréia) e as cultivares Lucy Brown, Verônica e Elisa.

A matéria seca da parte aérea das plantas foi moída e subamostras foram trituradas em almofariz para passar em peneira de $0,355 \mathrm{~mm}$ (42 mesh) de abertura de malha. A extração do nitrato foi feita com água desionizada e os procedimentos empregados na sua quantificação foram o da coluna redutora contendo $\mathrm{Cd}$ (Follett \& Ratcliff, 1963), o da destilação (Bremner \& Keeney, 1965), o que utiliza o ácido salicílico (Cataldo et al., 1975) e o procedimento que emprega mistura redutora contendo Zn (Ulrich, 1948), que está descrito no protocolo analítico de Moraes \& Cantarella (2003).

Em todas as determinações de nitrato foram utilizados reagentes p.a. e foi feita uma prova em branco com água desionizada a cada 10 amostras. 


\section{Procedimento da coluna redutora contendo cádmio (Follett \& Ratcliff, 1963)}

Para frascos de plástico com tampa de pressão e capacidade de $100 \mathrm{~mL}$, foram transferidas amostras de $0,5 \mathrm{~g}$ de matéria seca e $50 \mathrm{~mL}$ de água desionizada, que foram submetidas, por 1 hora, a períodos de agitação de $5 \mathrm{~min}$, seguidos de $15 \mathrm{~min}$ de repouso, em banho-maria com temperatura em torno de $60^{\circ} \mathrm{C}$. Na clarificação dos extratos, as suspensões foram transferidas para balões volumétricos de $200 \mathrm{~mL}$, aos quais se adicionaram $5 \mathrm{~mL}$ de solução de tetraborato de sódio $\left(\mathrm{Na}_{2} \mathrm{~B}_{4} \mathrm{O}_{7} \cdot 10 \mathrm{H}_{2} \mathrm{O}\right)$ $50 \mathrm{~g} \mathrm{~L}^{-1} ; 5 \mathrm{~mL}$ de hexacianoferrato (II) de potássio $\left[\mathrm{K}_{4} \mathrm{Fe}(\mathrm{CN})_{6} .3 \mathrm{H}_{2} \mathrm{O}\right] 150 \mathrm{~g} \mathrm{~L}^{-1}$; e $5 \mathrm{~mL}$ de sulfato de zinco $\left(\mathrm{ZnSO}_{4} \cdot 7 \mathrm{H}_{2} \mathrm{O}\right) 300 \mathrm{~g} \mathrm{~L}^{-1}$. Após a adição de cada solução foi feita agitação do conteúdo, completando-se o volume com água desionizada e mantendo-se em repouso por $30 \mathrm{~min}$. A seguir, o material foi filtrado em papel-filtro qualitativo (extrato A). Alíquotas de $20 \mathrm{~mL}$ do extrato A foram transferidas para béqueres, receberam $5 \mathrm{~mL}$ de solução-tampão pH 9,6-9,7 (mistura de $\mathrm{HCl} 0,24 \mathrm{~mol} \mathrm{~L}^{-1}$ e $\mathrm{NH}_{4} \mathrm{OH} 0,75 \mathrm{~mol} \mathrm{~L}^{-1}$ ) e $2 \mathrm{~mL}$ de solução de EDTA $50 \mathrm{~g} \mathrm{~L}^{-1}$. Logo após, foram percoladas em coluna contendo Cd esponjoso (Lara et al., 1978), a uma vazão inferior a $10 \mathrm{~mL} \mathrm{~min}^{-1}$ e recolhidas em balões volumétricos de $100 \mathrm{~mL}$. A lavagem da coluna foi feita com várias porções de água desionizada, até completar o volume do balão (extrato B). Alíquotas de $10 \mathrm{~mL}$ dos extratos B foram transferidas para balões volumétricos de $50 \mathrm{~mL}$, aos quais se adicionaram $5 \mathrm{~mL}$ de solução de sulfanilamida $\left(\mathrm{C}_{6} \mathrm{H}_{8} \mathrm{~N}_{2} \mathrm{O}_{2} \mathrm{~S}\right) 5 \mathrm{~g} \mathrm{~L}^{-1} \mathrm{em}$ $\mathrm{HCl} 6 \mathrm{~mol} \mathrm{~L}^{-1}$. Após 3 min de repouso, adicionaram-se $3 \mathrm{~mL}$ de solução de cloreto de alfa-naftiletilenodiamina $\left(\mathrm{C}_{12} \mathrm{H}_{16} \mathrm{Cl}_{2} \mathrm{~N}_{2}\right) 5 \mathrm{~g} \mathrm{~L}^{-1} \mathrm{e}$, então, os volumes foram completados com água desionizada. Depois de $15 \mathrm{~min}$ de repouso, foram feitas leituras da absorbância a $540 \mathrm{~nm}$ em espectrofotômetro Cecil CE 1011. Os valores obti-

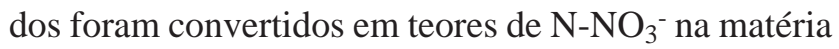
seca da alface com auxílio de uma curva de calibração preparada a partir de alíquotas de solução de $\mathrm{NaNO}_{2}$. Para tanto, foi considerado que o $\mathrm{N}^{-\mathrm{NO}_{2}}{ }^{-}$determinado foi proveniente da redução do nitrato por meio da passagem dos extratos pela coluna e que os teores originais de $\mathrm{N}-\mathrm{NO}_{2}{ }^{-}$na matéria seca das plantas eram desprezíveis.

A eficiência da coluna foi estimada a cada 15 amostras pela passagem de solução-padrão de $\mathrm{NaNO}_{3} 10 \mathrm{mg} \mathrm{L}{ }^{-1}$, e a taxa de recuperação de nitrato foi, em média, de $96 \%$.
Segundo Lara et al. (1978), a atividade do Cd esponjoso decresce ao longo do tempo. Assim, no início de cada dia de análise e após a passagem de alíquotas de 3 amostras pela coluna, ela foi reativada pela passagem de $25 \mathrm{~mL}$ de $\mathrm{HCl}$ 0,1 $\mathrm{mol} \mathrm{L}^{-1}, 50 \mathrm{~mL}$ de água desionizada e 25 mL de solução-tampão pH 9,6-9,7 diluída a 1:9 (v/v) com água desionizada.

\section{Procedimento da destilação (Bremner \& Keeney, 1965)}

A extração de nitrato foi semelhante à realizada no procedimento anterior, tendo sido utilizados $0,2 \mathrm{~g}$ de matéria seca e $20 \mathrm{~mL}$ de água desionizada. Após a extração, o material foi filtrado em papel-filtro qualitativo e foi feita a destilação dos extratos em microdestilador Kjeldahl (Bremner \& Keeney, 1965). Como uma adaptação para tecido vegetal, empregaram-se $5 \mathrm{~mL}$ de extrato e $0,4 \mathrm{~g}$ de liga de Devarda, para que todo o nitrato da amostra fosse convertido a amônio em uma única destilação. A seguir, foi feita a quantificação de $\mathrm{N}$ na forma de amônio do destilado por meio de titulação com solução padronizada de $\mathrm{H}_{2} \mathrm{SO}_{4} 0,00263 \mathrm{~mol} \mathrm{~L}^{-1}$. Considerou-se que a concentração de $\mathrm{N}-\mathrm{NO}_{2}{ }^{-}$presente nas amostras era desprezível e, assim, os resultados de $\mathrm{N}-\mathrm{NO}_{3}{ }^{-}+\mathrm{N}_{-} \mathrm{NO}_{2}{ }^{-}$foram convertidos e expressos

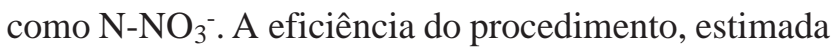

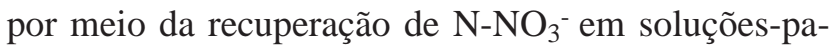
drão contendo $0,25,50,100,150,200,250$ e $300 \mathrm{mg} \mathrm{L}^{-1}$ de $\mathrm{N}-\mathrm{NO}_{3}{ }^{-}$foi, em média, de $104 \%$.

\section{Procedimento do ácido salicílico (Cataldo et al., 1975)}

A extração de nitrato foi semelhante à empregada no procedimento 1 , utilizando-se $0,1 \mathrm{~g}$ de matéria seca e $10 \mathrm{~mL}$ de água desionizada. Após a extração, foi adicionado, por meio de medida calibrada, $0,5 \mathrm{~g}$ de carvão ativado por amostra para a obtenção de extratos incolores. Após agitação e repouso de $10 \mathrm{~min}$, o material foi filtrado em papel-filtro quantitativo de filtragem lenta. Alíquotas de $0,2 \mathrm{~mL}$ de extrato receberam $0,8 \mathrm{~mL}$ de solução de ácido salicílico $\left(\mathrm{HC}_{7} \mathrm{H}_{5} \mathrm{O}_{3}\right) 50 \mathrm{~g} \mathrm{~L}^{-1} \mathrm{em} \mathrm{H}_{2} \mathrm{SO}_{4}$ concentrado e $19 \mathrm{~mL}$ de $\mathrm{NaOH} 2 \mathrm{~mol} \mathrm{~L}^{-1}$ e em seguida foi feita leitura da absorbância a $410 \mathrm{~nm}$. Os resultados foram convertidos em teores de $\mathrm{N}_{-} \mathrm{NO}_{3}{ }^{-}$na matéria seca das plantas, com o auxílio de uma curva de calibração preparada a partir de soluções diluídas de $\mathrm{NaNO}_{3}$, que receberam o mesmo tratamento dado às amostras. 
Procedimento da mistura redutora contendo $\mathrm{Zn}$ (Ulrich, 1948 modificado)

A extração do nitrato e o tratamento dos extratos com carvão ativado foram realizados de forma idêntica à do procedimento anterior, tendo sido utilizados $0,3 \mathrm{~g}$ de matéria seca e $30 \mathrm{~mL}$ de água desionizada. Alíquotas de $1 \mathrm{~mL}$ de extrato foram transferidas para tubos de ensaio, juntamente com $4 \mathrm{~mL}$ de água desionizada e $10 \mathrm{~mL}$ de solução de ácido acético $1,75 \mathrm{~mol} \mathrm{~L}^{-1}$. Após agitação, acrescentaram-se, por meio de medida calibrada, $0,5 \mathrm{~g}$ de mistura redutora obtida pela moagem em almofariz de 10,0 g de sulfato de bário $\left(\mathrm{BaSO}_{4}\right), 0,1 \mathrm{~g}$ de $\mathrm{Zn}$ em pó e $1,0 \mathrm{~g}$ de sulfato de manganês $\left(\mathrm{MnSO}_{4} \cdot \mathrm{H}_{2} \mathrm{O}\right)$. Em seguida, adicionou-se $1 \mathrm{~mL}$ do reagente cromogênico, preparado a partir de $0,125 \mathrm{~g}$ de alfa-naftilamina $\left(\mathrm{C}_{10} \mathrm{H}_{9} \mathrm{~N}\right)$ e $0,125 \mathrm{~g}$ de ácido sulfanílico $\left(\mathrm{C}_{6} \mathrm{H}_{7} \mathrm{NO}_{3} \mathrm{~S} . \mathrm{H}_{2} \mathrm{O}\right)$, dissolvidos em $50 \mathrm{~mL}$ de solução de ácido acético $1,75 \mathrm{~mol} \mathrm{~L}^{-1}$. O material foi agitado vigorosamente, mantido em repouso por $10 \mathrm{~min}$ e filtrado, utilizando-se funis de vidro de cerca de $5 \mathrm{~cm}$ de diâmetro e papel-filtro de filtração lenta. A seguir, foi feita leitura espectrofotométrica da absorbância a $540 \mathrm{~nm}$, em até 20 min após a filtração.

A cada dia de análise, foi feita uma curva de calibração a partir de alíquotas de solução de $\mathrm{KNO}_{3}$, as quais receberam tratamento idêntico ao dado às amostras. Com o auxílio da curva de calibração, os valores de absorbância foram convertidos em teores de $\mathrm{N}^{-\mathrm{NO}_{3}}{ }^{-}$ na matéria seca das plantas.

Os teores de $\mathrm{N}^{-\mathrm{NO}_{3}}{ }^{-}$na matéria seca das plantas, obtidos em cada procedimento, foram convertidos em teores do íon nitrato $\left(\mathrm{NO}_{3}{ }^{-}\right)$. $\mathrm{Na}$ avaliação dos efeitos das doses de $\mathrm{N}$ e de cultivares, os resultados foram submetidos à análise de variância em esquema fatorial $5 \times 3$ e ao teste de Tukey, a 5\% de probabilidade. Na comparação dos procedimentos de determinação de nitrato, foi feita análise de variância em parcelas subdivididas, sendo considerados 15 tratamentos principais (cinco doses de $\mathrm{N}$ e três cultivares de alface) com quatro repetições e quatro subtratamentos (procedimentos de quantificação de nitrato), e as médias foram comparadas pelo teste de Tukey, a 5\% de probabilidade.

\section{Resultados e Discussão}

Em todos os procedimentos de quantificação foram detectados efeitos significativos das doses de $\mathrm{N}$ no teor de nitrato e diferenças entre as cultivares de alface, o que gerou uma faixa ampla de teores, conveniente para avaliação dos procedimentos para determinação do íon (Tabela 1).

Com o procedimento de Cataldo et al. (1975), foram obtidos teores de nitrato maiores do que com os demais. De acordo com a análise estatística, os valores encontrados para os teores de nitrato seguiram a seguinte seqüência: ácido salicílico (Cataldo et al., 1975) > mistura redutora (Ulrich, 1948, modificado) $>$ coluna redutora (Follett \& Ratcliff, 1963) = destilação (Bremner \& Keeney, 1965), sendo que os teores de $\mathrm{NO}_{3}{ }^{-}$obtidos com o uso dos procedimentos do ácido salić́lico e da mistura redutora contendo $\mathrm{Zn}$ foram, em média, $241 \%$ e $46 \%$ maiores, respectivamente, do que os encontrados com o procedimento da coluna redutora.

Tabela 1. Teores de $\mathrm{NO}_{3}^{-}\left(\mathrm{g} \mathrm{kg}^{-1}\right)$ na matéria seca de alface, obtidos por quatro procedimentos de quantificação. Médias de quatro repetições.

\begin{tabular}{|c|c|c|c|c|}
\hline Variáveis $^{(1)}$ & $\begin{array}{l}\text { Coluna } \\
\text { redutora }\end{array}$ & Destilação & $\begin{array}{c}\text { Ácido } \\
\text { salicílico }\end{array}$ & $\begin{array}{l}\text { Mistura } \\
\text { redutora }\end{array}$ \\
\hline $\mathrm{N}_{0} \mathrm{C}_{1}$ & 2,87 & 2,57 & 13,57 & 3,60 \\
\hline $\mathrm{N}_{1} \mathrm{C}_{1}$ & 6,63 & 6,11 & 18,06 & 7,32 \\
\hline $\mathrm{N}_{2}^{1} \mathrm{C}_{1}$ & 11,43 & 10,03 & 24,11 & 13,73 \\
\hline $\mathrm{N}_{3}^{2} \mathrm{C}_{1}$ & 20,80 & 19,11 & 33,76 & 21,91 \\
\hline $\mathrm{N}_{4} \mathrm{C}_{1}$ & 34,14 & 33,95 & 43,11 & 33,47 \\
\hline$\overline{\mathrm{N}_{0} \mathrm{C}_{2}}$ & 1,50 & 1,17 & 10,34 & 3,57 \\
\hline $\mathrm{N}_{1} \mathrm{C}_{2}$ & 3,96 & 3,52 & 13,17 & 7,19 \\
\hline $\mathrm{N}_{2} \mathrm{C}_{2}^{2}$ & 5,18 & 4,18 & 17,32 & 7,87 \\
\hline $\mathrm{N}_{3}^{2} \mathrm{C}_{2}^{2}$ & 12,00 & 10,99 & 24,99 & 13,60 \\
\hline $\mathrm{N}_{4} \mathrm{C}_{2}$ & 29,89 & 30,48 & 40,86 & 28,72 \\
\hline $\mathrm{N}_{0} \mathrm{C}_{3}$ & 1,29 & 1,92 & 10,70 & 3,18 \\
\hline $\mathrm{N}_{1} \mathrm{C}_{3}$ & 2,33 & 2,15 & 13,12 & 4,63 \\
\hline $\mathrm{N}_{2} \mathrm{C}_{3}$ & 3,79 & 3,26 & 14,45 & 5,80 \\
\hline $\mathrm{N}_{3} \mathrm{C}_{3}$ & 10,59 & 10,68 & 24,21 & 12,69 \\
\hline $\mathrm{N}_{4} \mathrm{C}_{3}$ & 21,47 & 21,37 & 37,11 & 26,70 \\
\hline Médias $^{(2)}$ & $11,37 \mathrm{C}$ & $10,77 \mathrm{C}$ & $22,59 \mathrm{~A}$ & $12,93 \mathrm{~B}$ \\
\hline \multicolumn{5}{|c|}{ Valores do teste F } \\
\hline Nitrogênio (N) & $248,81 * *$ & $179,26^{* *}$ & $88,88 * *$ & $86,86 * *$ \\
\hline Cultivares (C) & $55,98 * *$ & $27,26 * *$ & $13,27 * *$ & $10,25^{* *}$ \\
\hline $\mathrm{NxC}$ & $6,08 * *$ & $3,61 * *$ & $0,69^{\text {ns }}$ & $1,23^{\mathrm{ns}}$ \\
\hline DMS (N) & 2,77 & 3,28 & 4,97 & 4,52 \\
\hline DMS (C) & 1,83 & 2,17 & 3,28 & 2,98 \\
\hline $\mathrm{CV}(\%)$ & 21 & 26 & 19 & 30 \\
\hline \multicolumn{4}{|c|}{ Procedimentos $(\mathrm{P})$} & $212,12 * *$ \\
\hline \multicolumn{4}{|c|}{$\mathrm{P} x$ variáveis } & $0,76^{\mathrm{ns}}$ \\
\hline \multicolumn{4}{|l|}{ DMS para $\mathrm{P}$} & 1,39 \\
\hline
\end{tabular}

${ }^{(1)} \mathrm{N}_{0}, \mathrm{~N}_{1}, \mathrm{~N}_{2}, \mathrm{~N}_{3}$ e $\mathrm{N}_{4}$ correspondem, respectivamente, a 0, 141,5, 283, 566 e $1.132 \mathrm{mg} /$ vaso de $\mathrm{N}$, como uréia, e $\mathrm{C}_{1}, \mathrm{C}_{2}$ e $\mathrm{C}_{3}$, às cultivares Lucy Brown, Verônica e Elisa. ${ }^{(2)}$ Médias seguidas de mesma letra não diferem

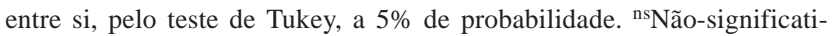
vo. **Significativo a $1 \%$ de probabilidade. 
Diferenças entre procedimentos de quantificação de nitrato em extratos de planta também foram observadas por Jackson (1980), Taber \& Killorn (1993), Anderson \& Case (1999) e Salomez \& Hofman (2002). Apesar das diferenças observadas nos teores de nitrato, os procedimentos testados apresentaram comportamento semelhante ao da coluna redutora que, nesse caso, foi considerado como padrão, tendo em vista que é usado no método oficial de determinação de nitrato em carnes e demais alimentos e apresenta boa exatidão (Brasil, 1999). Os coeficientes de correlação foram todos altos e significativos (Figura 1).

A exatidão no procedimento da coluna redutora, associada aos resultados obtidos, evidencia que a quantificação de nitrato em extratos de planta pelos procedimentos do ácido salicílico e da mistura redutora, especialmente o do ácido salicílico (Cataldo et al., 1975), superestimam os teores do íon. Fatores como a presença de íons interferentes (Sah, 1994), a coloração do extrato, apesar da aparente eliminação da cor pelo carvão ativado e o uso de pequenas alíquotas de extrato $(0,2 \mathrm{~mL})$, que aumenta a possibilidade de erros, podem justificar os resultados obtidos com o uso do ácido salicílico. Desses fatores, a coloração do extrato pode ter sido a causa principal da obtenção de teores superestimados, pois, na reação do ácido salicílico com o nitrato, em meio ácido, forma-se composto de cor amarela, mesma coloração dos extratos de matéria seca de alface. Assim, o uso de carvão ativado pode não ter sido suficiente na eliminação completa da cor, e a cor residual pode ter afetado de maneira mais intensa a quantificação do nitrato pelo procedimento do ácido salicílico do que por aquele que emprega mistura redutora contendo $\mathrm{Zn}$, em que a cor obtida é rosa, e a leitura espectrofotométrica é feita a $540 \mathrm{~nm}$.

Cataldo et al. (1975), quando propuseram o procedimento do ácido salicílico na quantificação de nitrato em plantas, empregaram amostras de milho e aveia, e obtiveram extratos incolores com o uso de matéria seca e coloridos com o uso de matéria fresca. Para eliminar a interferência da cor, recomendaram o emprego de uma prova em branco por amostra. Essa conduta, que torna a análise mais trabalhosa e demorada, foi testada, e constatou-se que os teores de nitrato na matéria seca de alface obtidos deste modo foram, em média, $50 \%$ menores do que aqueles nos quais se utilizou carvão ativado.
No caso do procedimento da coluna redutora, que também é colorimétrico, o uso de soluções clarificantes
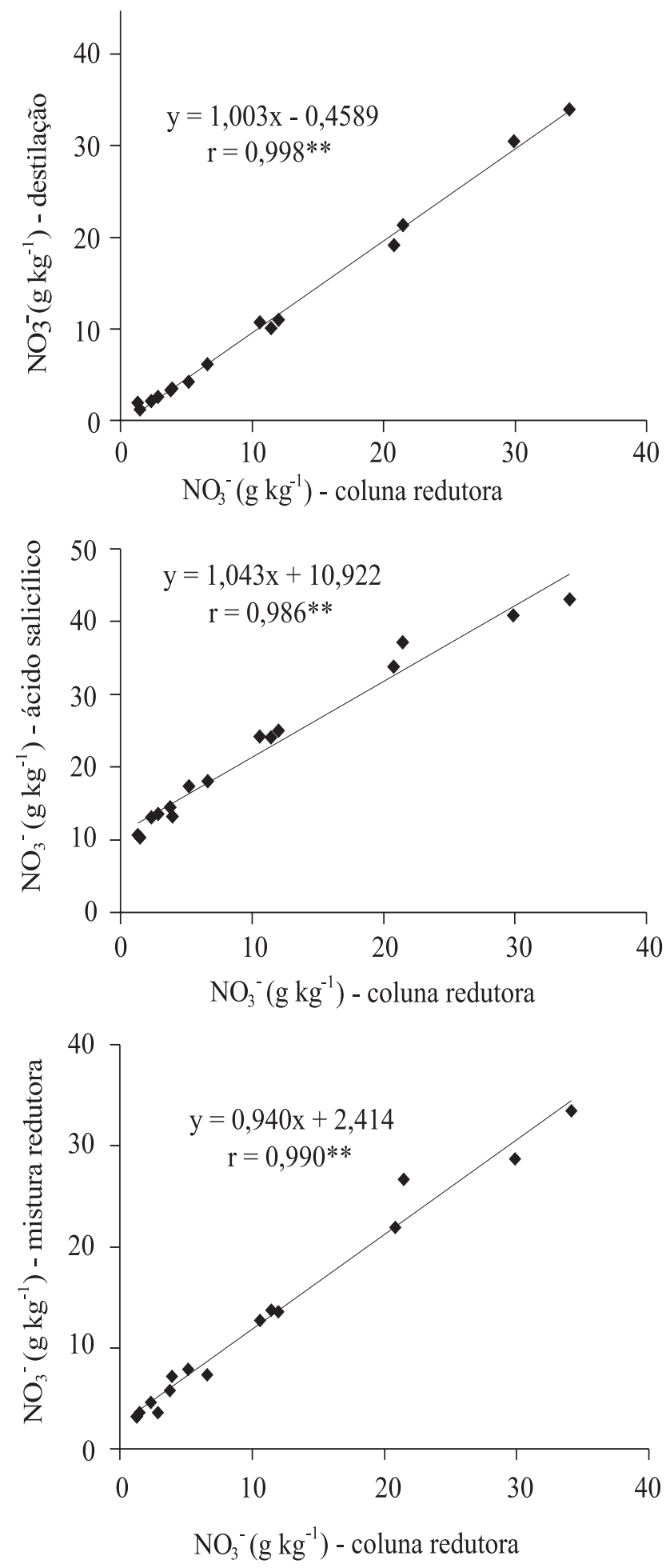

Figura 1. Correlações entre os procedimentos de quantificação de nitrato na matéria seca das plantas. **Significativo a $1 \%$ de probabilidade pelo teste $\mathrm{F}$. 
$\left(\mathrm{Na}_{2} \mathrm{~B}_{4} \mathrm{O}_{7} \cdot 10 \mathrm{H}_{2} \mathrm{O}, \mathrm{K}_{4} \mathrm{Fe}(\mathrm{CN})_{6} \cdot 3 \mathrm{H}_{2} \mathrm{O}\right.$ e $\left.\mathrm{ZnSO}_{4} \cdot 7 \mathrm{H}_{2} \mathrm{O}\right)$ e a diluição do extrato com água desionizada, após sua passagem pela coluna, eliminaram por completo a interferência da cor na quantificação do íon, pois os valores obtidos foram similares aos encontrados no procedimento de destilação, que não sofre influência desse fator.

Entre os procedimentos avaliados, o da coluna redutora possui maior sensibilidade que os demais, pois, seu limite de detecção para nitrato é de $0,02876 \mathrm{mg} \mathrm{mL}^{-1}$, o que corresponde a um teor na matéria seca das plantas de $65 \mathrm{mg} \mathrm{kg}^{-1}$. Por outro lado, os procedimentos de destilação, do ácido salicílico e da mistura redutora contendo Zn são mais adequados para amostras de matéria seca contendo teores de nitrato acima de 560, 500 e $400 \mathrm{mg} \mathrm{kg}^{-1}$, respectivamente, embora, de acordo com seus autores, amostras com teores menores do que os citados possam ser analisadas, diminuindo a relação massa de matéria seca:solução extratora, ou, no caso do procedimento de destilação, aumentando a alíquota do extrato a ser destilada.

Dos quatro procedimentos testados, o do ácido salicílico e o da coluna redutora foram os que apresentaram os menores coeficientes de variação e, deste modo, de acordo com Raij et al. (1987), podem ser considerados os mais precisos (Tabela 1).

A exatidão, a precisão e a sensibilidade são parâmetros que devem ser considerados na escolha de um procedimento de análise. No caso da análise de nitrato, a exatidão é fundamental, pois há a necessidade de se obter a concentração real do íon na amostra para se saber se o alimento está ou não apropriado para o consumo. Dessa maneira, embora o uso do ácido salicílico tenha proporcionado boa precisão, os valores obtidos, a exemplo do que ocorreu com a mistura redutora contendo $\mathrm{Zn}$, foram superestimados, o que indica que esses procedimentos, especialmente o primeiro, não são adequados na quantificação de nitrato em tecido vegetal. Por outro lado, o procedimento da destilação foi o que mais se aproximou do procedimento da coluna redutora, pois os teores de nitrato obtidos em ambos os casos não diferiram estatisticamente, e os coeficientes de variação $(\mathrm{CV})$ também foram próximos. Dessa maneira, ambos podem ser usados na quantificação de nitrato em tecido vegetal. Entretanto, o uso da destilação apresenta vantagens em relação ao emprego da coluna redutora, ou seja, é menos trabalhoso, de menor custo, pois o número de reagentes utilizados é menor, e não expõe o analista a eventuais riscos de saúde pelo contato com o cádmio.
No caso do uso do procedimento de destilação para quantificação de nitrato em plantas, deve ser dada atenção especial às quantidades de extrato e de liga de Devarda a serem utilizadas, para que todo o nitrato da amostra seja convertido a amônio em uma única destilação. No presente trabalho, no qual empregaram-se doses de $\mathrm{N}$ e alface, planta acumuladora de nitrato, os teores obtidos foram altos, e, dessa maneira, os testes realizados mostraram a necessidade do uso de $5 \mathrm{~mL}$ de extrato e $0,4 \mathrm{~g}$ de liga de Devarda. Em outras condições, nos quais os teores de nitrato sejam menores, a quantidade de extrato pode ser aumentada, e/ou a quantidade de liga de Devarda pode ser diminuída.

\section{Conclusões}

1. Os procedimentos com a coluna redutora contendo cádmio e de destilação são os mais adequados na quantificação de nitrato em tecido vegetal.

2. A simplicidade e o menor custo da destilação, quando comparados com a coluna redutora, sugerem que a destilação deve ser preferida neste tipo de análise.

\section{Agradecimento}

À Fapesp, pela bolsa concedida a José Ricardo Mantovani.

\section{Referências}

ANDERSON, K.A.; CASE, T.E. Evaluation of plant nitrate extraction techniques and effect on commonly used analytical methods of detection. Communications in Soil Science and Plant Analysis, v.30, p.1479-1495, 1999.

BENINNI, E.R.Y.; TAKAHASHI, H.W.; NEVES, C.S.V.J.; FONSECA, I.C.B. Teor de nitrato em alface cultivada em sistemas hidropônico e convencional. Horticultura Brasileira, v.20, p.183186, 2002.

BRASIL. Ministério da Agricultura e do Abastecimento. Secretaria de Defesa Agropecuária. Oficializa os métodos analíticos físicoquímicos para controle de produtos cárneos e seus ingredientes. Instrução Normativa n. 20, de 21 de julho de 1999. Diário Oficial [da] República Federativa do Brasil, Poder Executivo, Brasília, 09 set. 1999. Seção 1, p.30.

BREMNER, J.M.; KEENEY, D.R. Exchangeable ammonium, nitrate and nitrite by steam-distillation methods. In: BLACK, C.A. (Ed.). Methods of soil analysis: chemical and microbiological properties. Madison: American Society of Agronomy; Soil Science Society of America, 1965. p.1191-1206.

CASTRO, S.R.P.; FERRAZ JÚNIOR, A.S.L. Teores de nitrato nas folhas e produção da alface cultivada com diferentes fontes de nitrogênio. Horticultura Brasileira, v.16, p.65-68, 1998. 
CATALDO, D.A.; HAROON, M.; SCHRADER, L.E.; YOUNGS, V.L. Rapid colorimetric determination of nitrate in plant tissue by nitration of salicylic acid. Communications in Soil Science and Plant Analysis, v.6, p.71-80, 1975.

FOLLETT, M.J.; RATCLIFF, P.W. Determination of nitrite and nitrate in meat products. Journal of the Science of Food and Agriculture, v.14, p.138-144, 1963.

JACKSON, R.K. Avoiding interferences and problems in the determination of nitrate. The comparison of two methods: the orion specific ion electrode and the cadmium column. Communications in Soil Science and Plant Analysis, v.11, p.127134, 1980.

JOHNSON, C.M.; ULRICH, A. Determination of nitrate in plant material. Analytical Chemistry, v.22, p.1526-1529, 1950.

LARA, W.H.; TAKAHASHI, M.Y.; SILVEIRA, N. Determinação de nitritos e nitratos em conservas de carne. Revista do Instituto Adolfo Lutz, v.38, p.161-166, 1978.

LÉDO, F.J. da S.; CASALI, V.W.D.; MOURA, W.M.; PEREIRA, P.R.G.; CRUZ, C.D. Eficiência nutricional do nitrogênio em cultivares de alface. Revista Ceres, v.47, p.273-285, 2000.

MORAES, M.F.; CANTARELLA, H. Determinação de nitrato em plantas. Campinas: Instituto Agronômico, 2003. 2p. Protocolo analítico.

RAIJ, B. van; QUAGGIO, J.A.; CANTARELLA, H.; FERREIRA, M.E.; LOPES, A.S.; BATAGLIA, O.C. Análise química do solo para fins de fertilidade. Campinas: Fundação Cargill, 1987. 170p.
RICCI, M.S.F.; CASALI, V.W.D.; CARDOSO, A.A.; RUIZ, H.A. Teores de nutrientes em duas cultivares de alface adubadas com composto orgânico. Pesquisa Agropecuária Brasileira, v.30, p.1035-1039, 1995.

SAH, R.N. Nitrate-nitrogen determination - a critical review. Communications in Soil Science and Plant Analysis, v.25, p.28412869, 1994.

SALOMEZ, J.; HOFMAN, G. Nitrate extraction from fresh plant material by means of a methanol:water extraction solution. Communications in Soil Science and Plant Analysis, v.33, p.33973404, 2002.

SWANN, P.F. The toxicology of nitrate, nitrite and N-nitrous compounds. Journal of the Science of Food and Agriculture, v.26, p.1761-1770, 1975.

TABER, H.G.; KILLORN, R. Determination of nitrate in unfiltered extracts of muskmelon tissue by ion-selective electrodes. Communications in Soil Science and Plant Analysis, v.24, p.1231-1241, 1993.

ULRICH, A. Plant analysis - methods and interpretation of results. In: KITCHEN, H.B. (Ed.). Diagnostic techniques for soils and crops. Washington: The American Potash Institute, 1948. p.157-198.

WOLFF, I.A.; WASSERMAN, A.E. Nitrates, nitrites, and nitrosamines. Science, v.177, p.15-19, 1972.

ZAGO, V.C.P.; EVANGELISTA, M.R.; ALMEIDA, D.L. de; GUERRA, J.G.M.; NEVES, M.C.P.; RUMJANEK, N.G. Aplicação de esterco bovino e uréia na couve e seus reflexos nos teores de nitrato e na qualidade. Horticultura Brasileira, v.17, p.207-211, 1999. 